\title{
HYDRODYNAMIC RESPONSE OF THE DEEP TURBINE INSTALLATION-FLOATING CONCEPT
}

\author{
Jordi Serret $^{\dagger 1}$, Tim Stratford ${ }^{1}$, Philipp R. Thies ${ }^{2}$, Vengatesan Venugopal ${ }^{1}$, Tahsin Tezdogan ${ }^{3}$ \\ ${ }^{1}$ University of Edinburgh, Edinburgh, UK \\ 2University of Exeter, Penryn, UK \\ ${ }^{3}$ University of Strathclyde, Glasgow, UK
}

\begin{abstract}
Floating offshore wind turbine (FOWT) installations are progressing from the $R \& D$ stage to commercial installation projects. The prospective sites are situated in increasingly deeper water and further away from the shore. This paper presents the Deep Turbine Installation-Floating (DTI-F) concept, an innovative hybrid spar buoy-based FOWT capable of being able to raise and lower the tower and nacelle, which simplifies construction, installation, maintenance and decommissioning. The study is focused on the hydrodynamics of the moored floating system, and it is based on experimental and numerical modelling work. A 1:45 Froude scaled model of the DTI-F wind concept was tested using three different mooring configurations: i) three mooring lines, ii) four mooring lines, and iii) three mooring lines with a delta connection. Free decay and stiffness decay tests were carried out together with regular and irregular wave tests. The numerical study comprises diffraction (ANSYS AQWA) and time-domain modelling (OrcaFlex).

The experimental hydrostatic and hydrodynamic results are compared with the numerical simulations based on the as-built scale model. Considering the natural frequencies results obtained for the three mooring configurations, the three lines configuration without delta connection was selected as the most suitable design. The obtained results for the three mooring lines configuration show good agreement between the experiment and numerical simulations. The presented analysis of the design concept indicates a high degree of technical feasibility.
\end{abstract}

Keywords: Floating wind turbine; hydrodynamic response; aeroelasticity; numerical and experimental analysis.

\section{INTRODUCTION}

The offshore wind industry is experiencing noticeable growth during the last several years [1]. Since the quality of the wind resource increases with the distance from shore, harvesting wind in deeper waters will be an increasing source of renewable energy shortly [2]. In addition, the unfavourable social perception of the onshore wind developments along with the ambitious targets on renewable energy consumption, e.g. the European Commission has raised its target from $27 \%$ to $32 \%$ by 2030 , is boosting offshore wind developments and especially floating-based concepts, since floating offshore wind turbines (FOWT) are the only feasible solution for depths beyond $75 \mathrm{~m}$.

FOWT technology relies on numerical simulations to accurately predict the complex dynamics of the floating system and the offshore industry has developed powerful tools to simulate this coupled behaviour. However, as a new technology, the numerical models require experimental validation of these tools before moving into large-scale demonstrators. Moreover, large-scale developments will be based only on de-risked concepts able to demonstrate cost-effectiveness.

\subsection{DTI-F concept description}

The Deep Turbine Installation-Floating (DTI-F) concept is a hybrid spar buoy-based floating offshore substructure consisting of two cylindrical and concentric walls with a wider cylinder in the base joined to the top cylinders by means of a frustum-cone type structure. The space between the two cylinders provides the necessary buoyancy to the floater. The void space in the wider cylinder at the bottom is used to store the ballast water. The structure has a water-entrapment heave plate located below the wider cylinder, which provides additional hydrodynamic inertia to the floater in shallower installation depths.

Both the inner and wider cylinders are connected at the bottom end of the floater, allowing the tower and nacelle set to be raised and lowered down within the inner cylinder by flooding them using the ballast water (Fig. 1). A flotation cylinder, designed to counteract the weight of the tower and the nacelle, is installed at the bottom of the tower. This flotation cylinder is a critical component that allows both the tower and nacelle to float.

The active ballast system transfers water from the wider cylinder to the inner hollow cylinder to float the tower and nacelle set, allowing it to be raised and lowered, avoiding the use of expensive cranes during installation, maintenance and decommissioning processes.

\footnotetext{
† Contact author: J.Serret@ed.ac.uk
} 


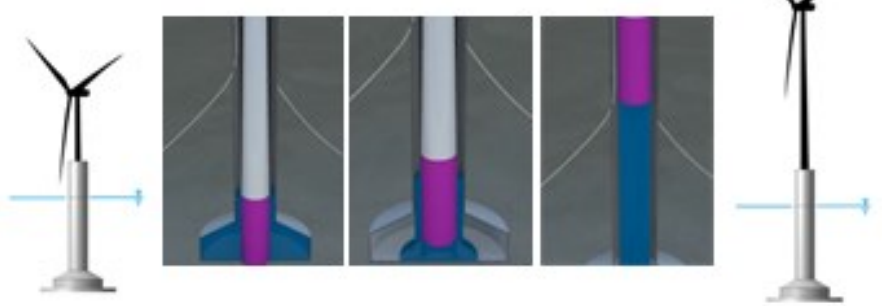

\section{FIGURE 1 RAISING MECHANISM SEQUENCE USING THE FLOTATION CYLINDER (PURPLE) ALONG WITH THE BALLAST WATER}

The capability of raising and lowering the tower and nacelle implies a geometry and mass distribution that presents stability challenges from the hydrostatic and hydrodynamic point of view. Therefore, this study aims to de-risk the DTI-F concept, before moving into large-scale demonstrators.

\subsection{Numerical models on FOWT}

There are several computational techniques available to simulate the behaviour of FOWT [3]. FOWT exhibit a strong coupling between some of their components. The wind field interacts with the blades through bending and rotation. Regardless of the gearing system used, the rotation of the rotor is transmitted to the shaft where the elasticity plays an important role. This rotatory motion is then transmitted to the generator which is also affected by the electric network. This set of loads are then communicated from the nacelle to the tower by the yaw system which will introduce a new stiffness to the system on top of the blades and shaft. The tower will receive the loads coming from the nacelle and the loads from the wind field that impact the tower (and affected by the pass-through of the blades while spinning). Again, the elasticity/bending of the tower will affect notably the transmission of the loads to the substructure.

Here, the substructure is modelled as a flexible body with a global solid-rigid motion, which will be finally transmitted to the anchoring system through the mooring lines. It is worth highlighting that any of these systems have complex dynamics on their own. Therefore, the level of complexity reached, once the simulation is fully-coupled is elevated. Moreover, the control system and the transmission piece effects should also be taken into account. In order to increase the fidelity of the simulations, the hydrodynamic interactions between the substructure and the moorings with waves and currents, e.g. ringing, vortex-induced vibrations (VIV) and the complicated soil-anchoring system interaction, will be investigated as part of future studies.

However, during the design and in the early stages of the development, the different interactions explained before can be isolated and simulated independently before joining them in a fully-coupled simulation, in order to reduce the level of complexity. This study thus deals solely with the uncoupled hydrodynamic behaviour of the DTI-F system.

To compute the hydrodynamic behaviour of FOWT, there is a wide range of techniques available. The most common empirical method used is Morison's equation [4]. Increasing the computational effort, the use of the Potential Flow (PF) models to compute linear wave-structure interaction using the panel method is another widely used technique due to its well-balanced accuracy vs computational effort ratio. However, PF assumes that viscosity does not play an important role; if this is not the case, Morison type models may be imposed to improve PF results. Finally, when considering advanced numerical methods, Computational Fluid Dynamics (CFD) models [4, 5] present a better agreement with experimental results when compared with PF and PF with Morison's equation results. However, the use of CFD is limited for design purposes, due to the computational effort involved.

Regarding the modelling of the mooring lines, two different approaches can be adopted, quasi-static or dynamic analysis.

This study focuses on validating an ANSYS AQWA simulation of the DTI-F concept without mooring lines. Subsequently, the ANSYS AQWA results are used as an input to simulate the platform and mooring dynamics using OrcaFlex. ANSYS AQWA 19.1 is a commercial software package using diffraction potential theory with an imposed Morison drag term, and OrcaFlex 10.2 is a dynamic mooring analysis commercial software package able to perform complex simulations including VIV effects among others.

\subsection{Hydrodynamic model testing of FOWT}

As stated before, the numerical models require experimental validation. Full-scale tests on the relevant environment [6], i.e. open sea, require considerable effort and expenditures. Therefore, scaled model testing is the first step to evaluate concept feasibility [7] or component performance [8] before moving to large/full-scale developments.

Experimental studies for spar-buoy FOWT started in Norway in 2005 preparing of the HYWIND concept [9], followed by experimental campaigns focused on semisubmersible [10] and later on Tension Leg Platforms (TLP) concepts [11]. Further hydrodynamic testing comparing the advantages and disadvantages of the three different concepts [12], analysing their performance for different site locations [13] or investigating the effect of their mooring lines [14] have been performed along with testing considering realistic wind and wave conditions [11], i.e. software-in-the-loop testing.

Although tank testing is subjected to undesirable scaling effects [15], small models are less costly and easier to handle. They require less staff and shorter set up and testing times and been a valuable tool to calibrate, validate, and verify numerical simulations early in the design process.

\section{EXPERIMENTAL METHODOLOGY}

This section describes the model test campaign carried out in the Ocean Wave Basin of the Lir NOTF in Cork (Ireland).

The wave basin is $15.14 \mathrm{~m}$ long and $25.85 \mathrm{~m}$ wide. There is a deep section $(11.2 \mathrm{~m} \times 10 \mathrm{~m})$ equipped with a moveable floor plate in the centre of the basin which was set to $2 \mathrm{~m}$ depth to conduct the testing.

During the testing, the height of the waves was measured by six resistive twin-wire probes. The floater motions were recorded 
by an optical tracking system, and the mooring line tensions were gauged using force transducers at the fairleads.

\subsection{Model description}

A 1:45 Froude scaled DTI-F system was constructed of divinycell closed cell foam sections with aluminium interfaces and heave plate (Fig.2). The design includes approximately 10 $\mathrm{kg}$ of moveable ballast in the upper cylinder to adjust the final draft and centre of gravity.

Table 1 and 2 present the dimensions of the model as built and the mass properties calculated through computer-aided design software (SolidEdge ST10). The centre of gravity ( $\mathrm{CoG}$ ) height is measured from the bottom of the structure and moments of inertia $\left(\mathrm{I}_{\mathrm{ii}}\right)$ are calculated at the $\operatorname{CoG}$. The tower and nacelle were modelled to match the mass distributions of the Levenmouth (Samsung Heavy Industries - S7.0-171) demonstration wind turbine as described in [16].
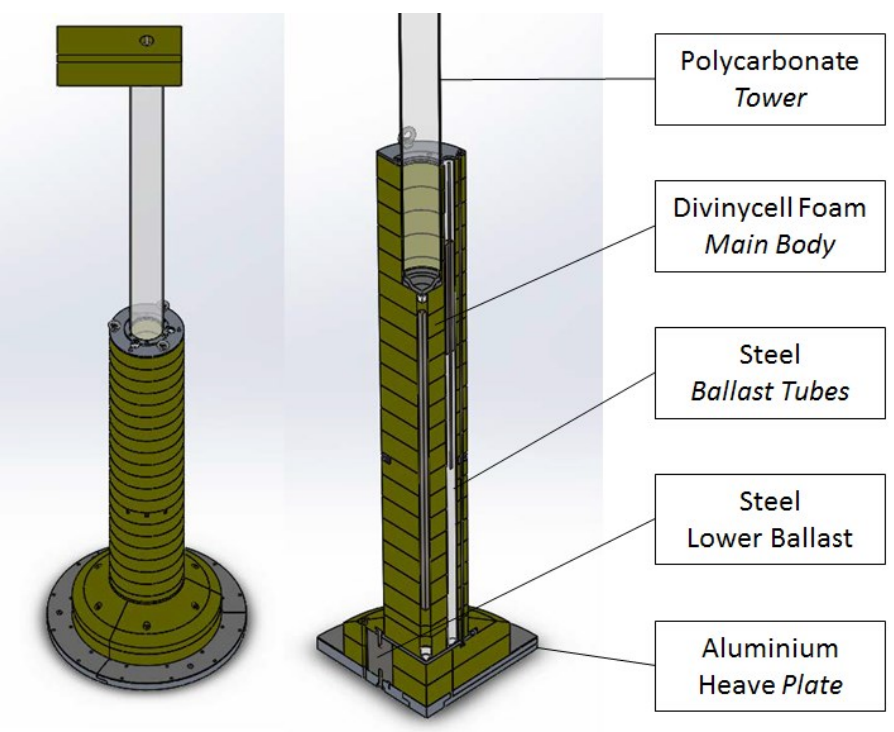

\section{FIGURE 2 MANUFACTURE DESIGN OF THE DTI-F. THE DRAWING ON THE RIGHT IS A QUADRANT SHOWING THE INNER STRUCTURE TABLE 1 DIMENSIONS OF THE DTI-F FROUDE SCALED MODEL}

\begin{tabular}{|lc|c|c|c|}
\cline { 2 - 5 } \multicolumn{1}{c|}{} & $\begin{array}{c}\text { Height } \\
(\mathrm{mm})\end{array}$ & $\begin{array}{c}\text { Width } \\
(\mathrm{mm})\end{array}$ & $\begin{array}{c}\text { Length } \\
(\mathrm{mm})\end{array}$ & $\begin{array}{c}\text { Diameter } \\
(\mathrm{mm})\end{array}$ \\
\hline DTI-F & 3651 & - & - & - \\
\hline Tip mass & 200 & 178 & 556 & - \\
\hline Tower & 1628 & - & - & 156 \\
\hline Top cylinder & 1556 & - & - & 333 \\
\hline Frustum & 111 & - & - & - \\
\hline Base cylinder & 111 & - & - & 667 \\
\hline Heave plate & 44 & - & - & 889 \\
\hline
\end{tabular}

TABLE 2 DTI-F MASS PROPERTIES.

\begin{tabular}{|c|c|c|c|c|c|}
\cline { 2 - 6 } \multicolumn{1}{c|}{} & $\begin{array}{c}\text { Mass } \\
(\mathrm{kg})\end{array}$ & $\begin{array}{c}\text { CoG } Z \\
(\mathrm{~mm})\end{array}$ & $\begin{array}{c}\text { Ixx } \\
\left(\mathrm{kgm}^{2}\right)\end{array}$ & $\begin{array}{c}I y y \\
\left(\mathrm{kgm}^{2}\right)\end{array}$ & $\begin{array}{c}I z z \\
\left(\mathrm{kgm}^{2}\right)\end{array}$ \\
\hline DTI-F & 186 & 447 & 126 & 126 & 10 \\
\hline
\end{tabular}

\subsection{Mooring lines}

The experiments include three different mooring configurations (Fig.3) using catenary lines: (a) three mooring lines distributed at 120 degrees, (b) four mooring lines distributed at 90 degrees, and (c) three mooring lines using a delta connection to join the mooring line and the substructure.

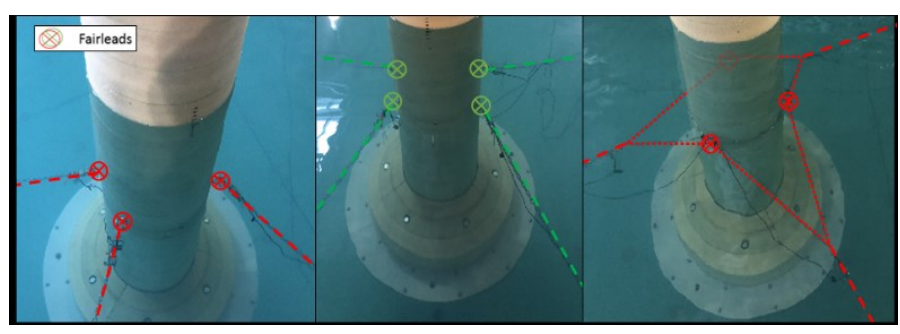
a) (3)
b) (4)
c) $\Delta$

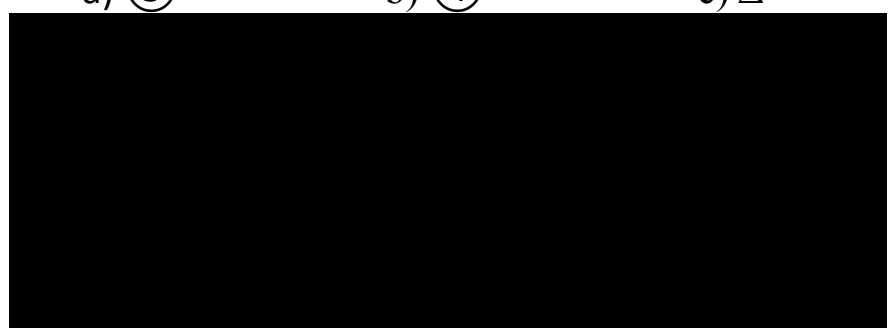

FIGURE 3 MOORING CONFIGURATIONS

The layout is shown in Figs.3 and 4. The delta connection setup uses the three lines layout along with the position of the movable floor, shown as a square. Further information regarding the mooring lines tested at Lir NOTF is provided in [14].

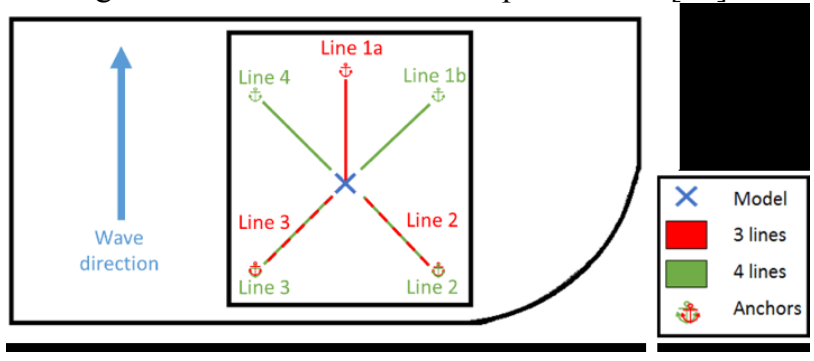

FIGURE 4 MOORING LAYOUT

Table 3 presents the length and mass per unit length of the different lines used to tie up the system. 
TABLE 3 DIMENSIONS OF THE DTI-F MODEL

\begin{tabular}{|l|c|c|}
\cline { 2 - 3 } \multicolumn{1}{c|}{} & Length $(\mathrm{m})$ & Mass per unit length $(\mathrm{kg} / \mathrm{m})$ \\
\hline Line 1a & 5.105 & 0.280 \\
\hline Line 1b & 5.355 & 0.196 \\
\hline Line 2 & 5.315 & 0.210 \\
\hline Line 3 & 5.315 & 0.210 \\
\hline Line 4 & 5.355 & 0.196 \\
\hline
\end{tabular}

\subsection{Testing conditions}

This section presents the different wave conditions tested to characterise the response of the DTI-F concept. Free decay tests were carried out for heave, pitch and roll modes of motion, whereas stiffness decay tests were also conducted for the surge, sway, and yaw modes of motions.

The objective is to define the resonance properties and hydrodynamic coefficients for the free floater and the complete system including the three different mooring line configurations.

Regular wave testing, simulating waves with amplitudes of 44 and $110 \mathrm{~mm}$ and periods ranging from 0.70 to 2.24 seconds were carried out to compute the displacements and the cable force response amplitude operators (RAOs).

Three irregular waves generated using the Joint North Sea Wave Observation Project (JONSWAP) spectrum with significant wave heights $\left(H_{s}\right)$ of 40,101 , and $150 \mathrm{~mm}$ and peak periods $\left(T_{p}\right)$ of $0.89,1.27$, and 1.41 seconds were also tested.

The experimental wave quality is depicted in Fig.5. It has been found that the wave height of the experiments is smaller than the target. The $44 \mathrm{~mm}$ waves were off by $23 \%$ for low frequencies arising until $27 \%$ for higher frequencies. The $110 \mathrm{~mm}$ waves present a $10 \%$ discrepancy with the target for low frequencies while for higher frequencies the experimental wave matches the target adequately.

The random wave experiments included line lost tests. The line lost tests are performed using the mentioned JONSWAP irregular seas but releasing some of the mooring lines sequentially during the test. The objective is characterising the behaviour of the structure with lost lines and producing the required data to investigate mooring line integrity and fatigue further.

Besides irregular waves using the JONSWAP spectrum, four different white noise waves have also been tested. Table 4 summarises the experiments conducted during the testing.

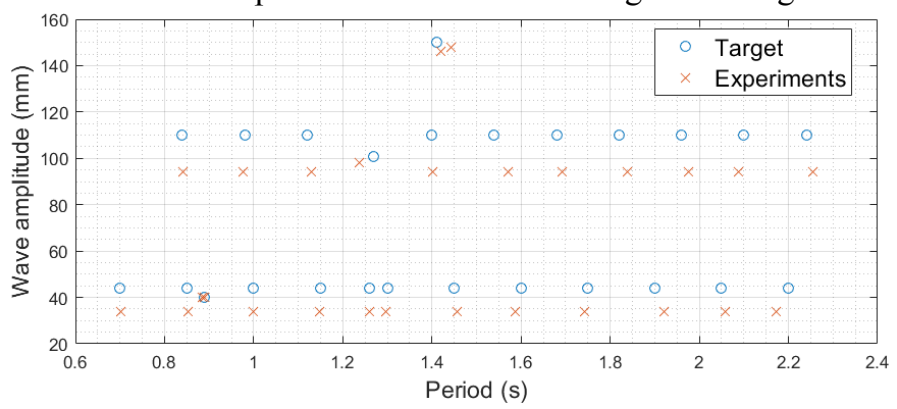

FIGURE 5 WAVE QUALITY
TABLE 4 TEST PROGRAMME

\begin{tabular}{|l|c|}
\hline Type of tests & Number of tests \\
\hline Free decay tests & 9 \\
\hline Stiffness decay tests & 36 \\
\hline Regular wave tests & 88 \\
\hline Irregular wave tests & 26 \\
\hline
\end{tabular}

\section{RESULTS}

This section presents the comparison between the experimental campaign measurements and the calibrated numerical simulations results. All the responses presented are at the CoG of the floating system.

\subsection{Decay tests}

Natural frequencies and damping ratios of the floating system with and without the mooring lines were computed from the results of the free decay and stiffness decay tests, respectively

Table 5 presents natural periods $\left(w_{n}\right)$ and damping coefficients $(\zeta)$ from the free decay tests and the diffraction numerical model.

\section{TABLE 5 RESONANCE PROPERTIES OF THE FREE} FLOATER

\begin{tabular}{|c|c|c|c|c|}
\cline { 2 - 5 } \multicolumn{1}{c|}{} & \multicolumn{2}{c|}{ Free decay test } & \multicolumn{2}{c|}{ ANSYS AQWA } \\
\cline { 2 - 5 } \multicolumn{1}{c|}{} & $w_{n}(\mathrm{~s})$ & $\zeta(-)$ & $w_{n}(\mathrm{~s})$ & $\zeta(-)$ \\
\hline Heave & 4.25 & $4.00 \times 10^{-3}$ & 4.25 & $4.14 \times 10^{-3}$ \\
\hline Pitch & 8.17 & $8.00 \times 10^{-4}$ & 8.17 & $8.11 \times 10^{-4}$ \\
\hline Roll & 8.17 & $8.00 \times 10^{-4}$ & 8.17 & $7.61 \times 10^{-4}$ \\
\hline
\end{tabular}

Figure 5 depicts the free decay time series for heave, pitch, and roll modes of motion, with a comparison between experimental and numerical simulation.

The ANSYS AQWA natural periods show a high degree of correlation with experimental measurements, almost overlaying the plotted traces. ANSYS AQWA damping coefficients are slightly higher for heave and pitch and lower for the roll mode of motion.

(a)

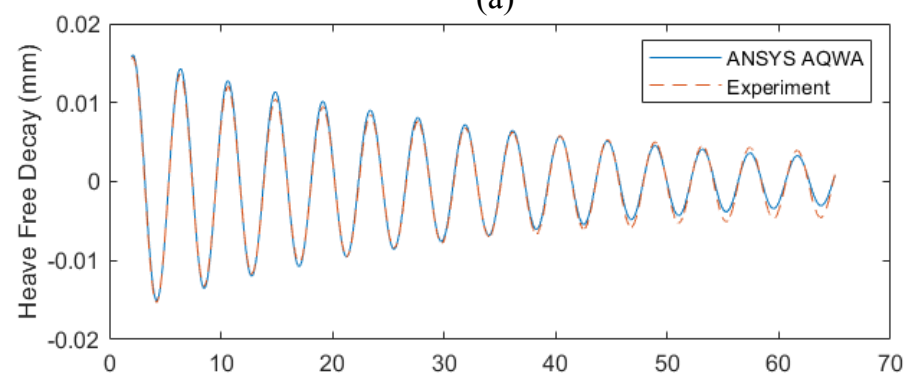

(b) 


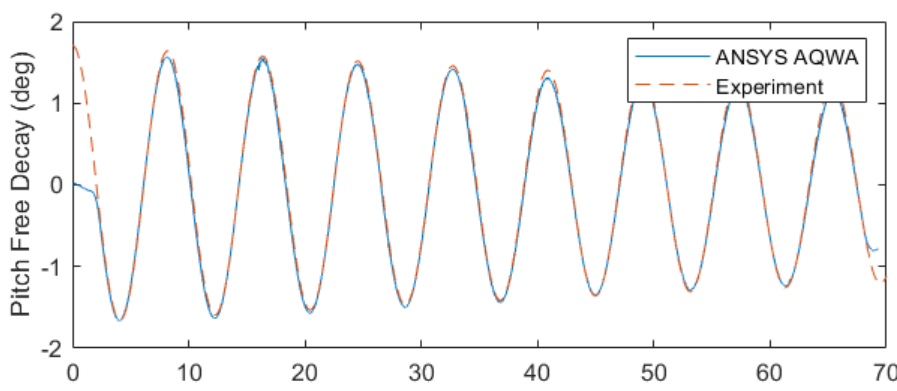

(c)

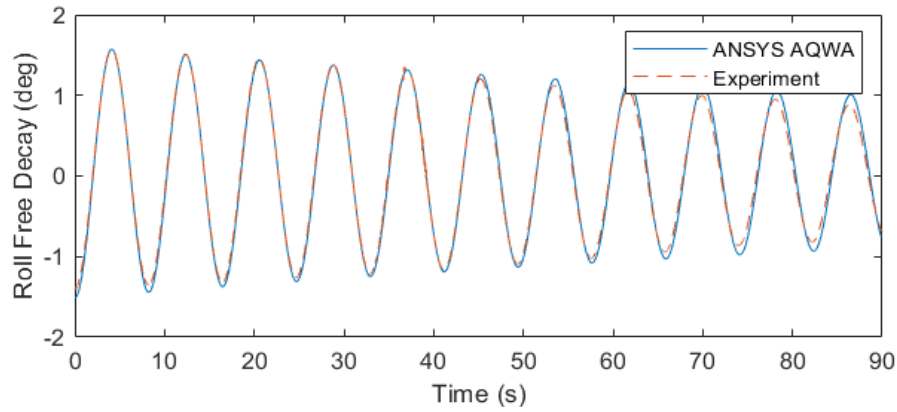

FIGURE 5 FREE DECAY RESPONSE IN HEAVE, PITCH, AND ROLL.

Table 6 shows the natural periods of oscillation and damping coefficients, characterising the DTI-F system for the three different mooring line configurations.

\section{TABLE 6 RESONANCE PROPERTIES OF THE DTI-F SYSTEM FOR THE THREE DIFFERENT MOORING CONFIGURATIONS}

\begin{tabular}{|c|c|c|c|c|c|c|}
\cline { 2 - 7 } \multicolumn{1}{c|}{} & \multicolumn{3}{c|}{$\zeta(-)$} & \multicolumn{3}{c|}{$w_{n}(\mathrm{~s})$} \\
\hline $\begin{array}{c}\text { Line } \\
\text { setup }\end{array}$ & 3 & $\Delta$ & 4 & 3 & $\Delta$ & 4 \\
\hline Heave & 0.004 & 0.004 & 0.004 & 1.495 & 1.495 & 1.495 \\
\hline Surge & 0.002 & 0.002 & 0.002 & 0.249 & 0.249 & 0.249 \\
\hline Sway & 0.002 & 0.002 & 0.002 & 0.417 & 0.417 & 0.417 \\
\hline Pitch & 0.001 & 0.0008 & 0.001 & 0.480 & 0.768 & 0.851 \\
\hline Roll & 0.001 & 0.0008 & 0.001 & 0.461 & 0.769 & 0.865 \\
\hline Yaw & 0.001 & 0.005 & 0.002 & 0.348 & 1.012 & 0.605 \\
\hline
\end{tabular}

Since the results of the stiffness decay tests for the four mooring lines and the three mooring lines with delta connection configurations do not improve the resonance properties of the system, only the three mooring lines configuration will be further discussed.
Table 7 presents the experimental and simulated natural periods of oscillation and the damping coefficient of the DTI-F system for the three mooring lines at 120 degrees configuration.

\section{TABLE 7 RESONANCE PROPERTIES OF THE DTI-F SYSTEM FOR THE THREE MOORING LINES AT 120 DEGREES CONFIGURATION}

\begin{tabular}{|l|c|c|c|c|}
\cline { 2 - 5 } \multicolumn{1}{c|}{} & \multicolumn{2}{c|}{ Stiffness decay test } & \multicolumn{2}{c|}{ OrcaFlex } \\
\cline { 2 - 5 } \multicolumn{1}{c|}{} & $w_{n}(\mathrm{~s})$ & $\zeta(-)$ & $w_{n}(\mathrm{~s})$ & $\zeta(-)$ \\
\hline Surge $\left(\mathrm{C}_{11}\right)$ & 0.249 & $1.97 \times 10^{-3}$ & 0.247 & $1.91 \times 10^{-3}$ \\
\hline Sway $\left(\mathrm{C}_{22}\right)$ & 0.417 & $2.17 \times 10^{-3}$ & 0.415 & $2.37 \times 10^{-3}$ \\
\hline Heave $\left(\mathrm{C}_{33}\right)$ & 1.495 & $3.54 \times 10^{-3}$ & 1.475 & $3.78 \times 10^{-3}$ \\
\hline Pitch $\left(\mathrm{C}_{44}\right)$ & 0.480 & $1.23 \times 10^{-3}$ & 0.475 & $1.54 \times 10^{-3}$ \\
\hline Roll $\left(\mathrm{C}_{55}\right)$ & 0.461 & $1.01 \times 10^{-3}$ & 0.467 & $1.28 \times 10^{-3}$ \\
\hline Yaw $\left(\mathrm{C}_{66}\right)$ & 0.348 & $1.36 \times 10^{-3}$ & 0.349 & $1.79 \times 10^{-3}$ \\
\hline
\end{tabular}

OrcaFlex natural periods present a reasonable correlation with experimental measurements. However, the predicted damping coefficients are slightly higher than the measured values, except for the yaw mode of motion.

Figure 6 shows the time-series of the stiffness decay test for (a) heave, (b) surge and (c) sway together with the results of the numerical simulations.

The simulated heave response matches the testing behaviour regarding the period of oscillation. However, the damping shows at small amplitude oscillations.

The surge response shows good agreement between experimental and simulated results. The overall response matches reasonably, but there is a mismatch in the troughs of the time-series.

The simulated sway response fits well with the testing measurements in terms of natural periods and damping. However, the time-series shows some coupling effects that the simulation is not able to reproduce.

Figure 7 shows the time-series of the stiffness decay test for (a) pitch, (b) roll, and (c) yaw along with the results of the numerical simulations.

The simulated results for the pitch and roll rotational modes of motion present good agreement regarding natural periods and damping with the experimental results, but show discrepancies in the amplitude of the harmonics.

The yaw response shows a reasonable agreement between experimental and simulated results, but there is a mismatch in the damping behaviour. 
(a)

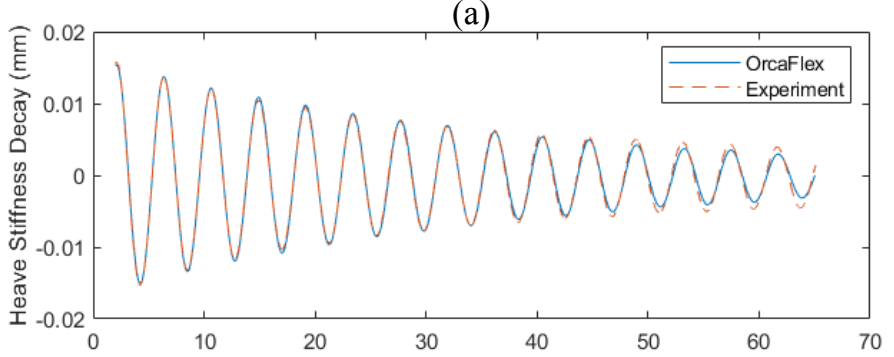

(b)

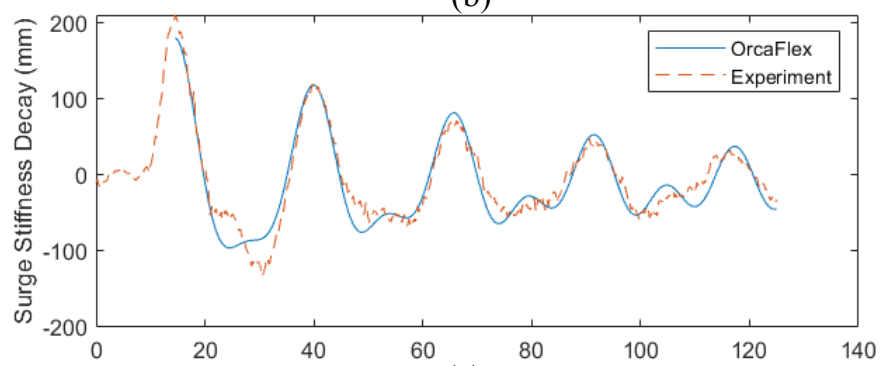

(c)

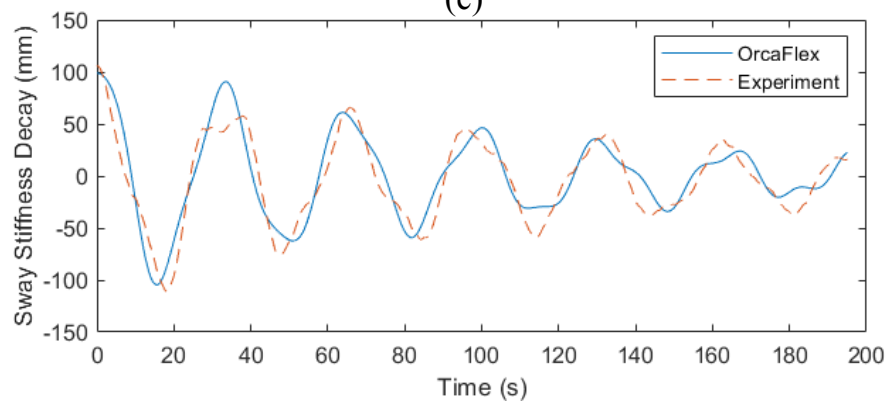

FIGURE 6 STIFFNESS DECAY RESPONSE FOR HEAVE, SURGE, AND SWAY MODES OF MOTION. ALL RESPONSES ARE AT COG OF THE FLOATING SYSTEM.

Using a series of static analyses, the model can be adjusted repeatedly until the mooring tension matches a target value. The natural period of oscillation depends mainly on the stiffness of the restricted floating system and its added mass [17]. Therefore, if the mass measurements correlate with the simulated displaced volume, the natural periods validate the added mass by elimination of other parameters.

\subsection{Regular wave tests}

Figures 8 and 9 show the motion RAOs for the six modes of motion. All six modes of motion show good agreement between the experimental results and numerical simulations. However, the pitch experimental results present dispersion from $1.5 \mathrm{~s}$ onwards.

Figure 10 presents the wave elevation, surge and pitch response time histories of the DTI-F model for a regular wave with a height of $44 \mathrm{~mm}$ and period of $2.22 \mathrm{~s}$. The measured and simulated responses showed a good match. (a)

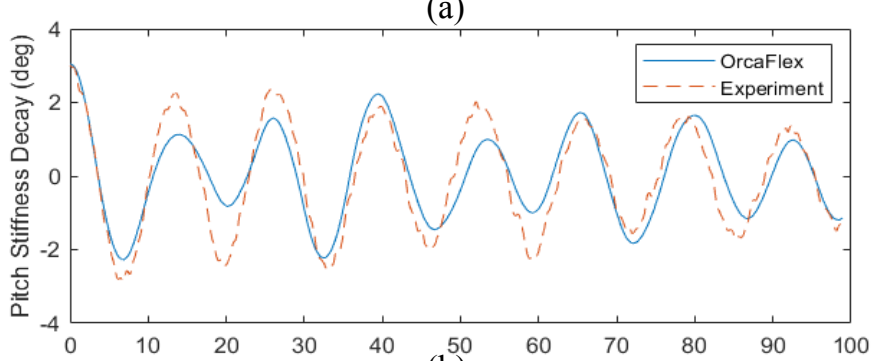

(b)

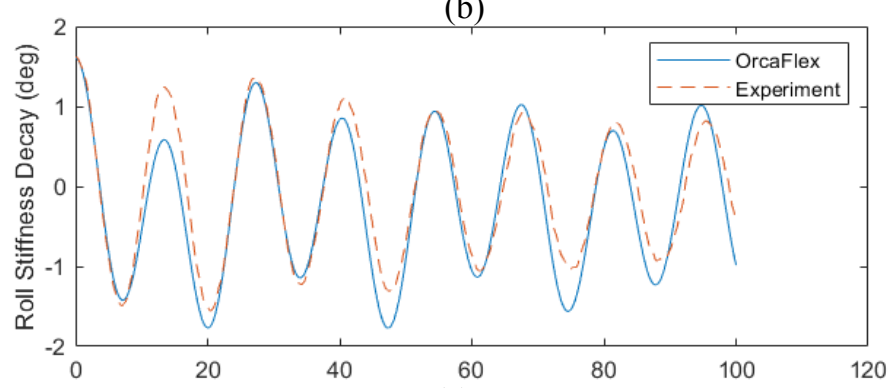

(c)

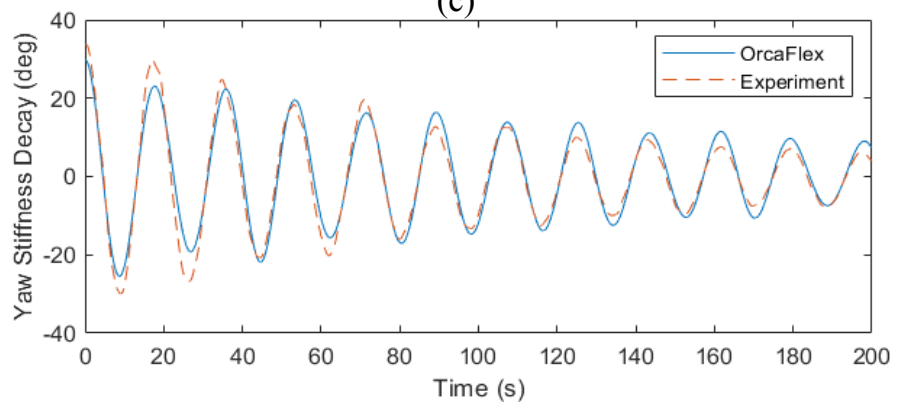

FIGURE 7 STIFFNESS DECAY RESPONSE FOR PITCH, ROLL, AND YAW MODES OF MOTION. ALL RESPONSES ARE AT COG OF THE FLOATING SYSTEM.

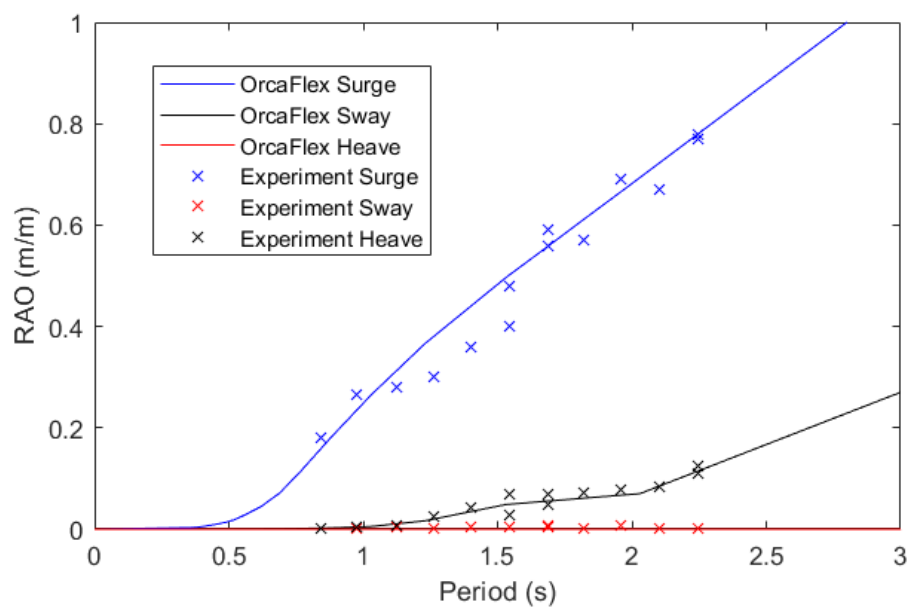

FIGURE 8 MOTION RAOS FOR SURGE, SWAY AND HEAVE. 


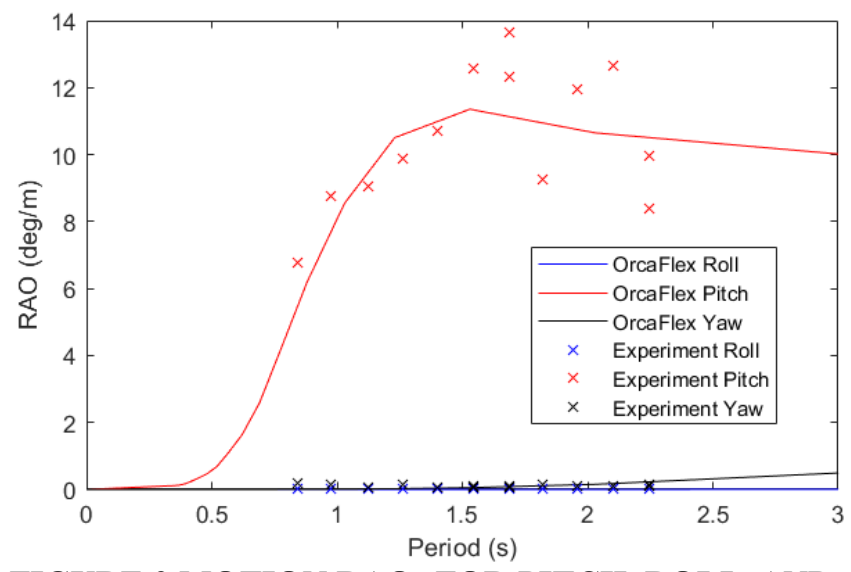

FIGURE 9 MOTION RAOS FOR PITCH, ROLL, AND YAW. ALL RESPONSES ARE AT COG OF THE FLOATING SYSTEM.

(a)

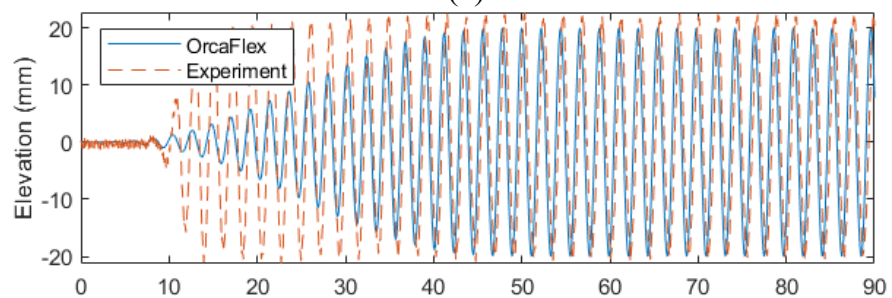

(b)

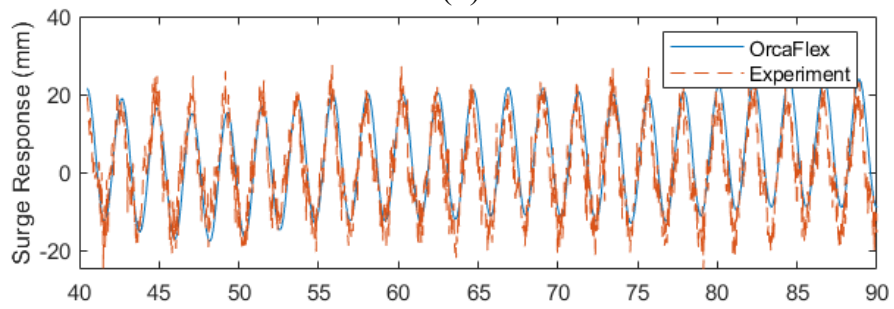

(c)

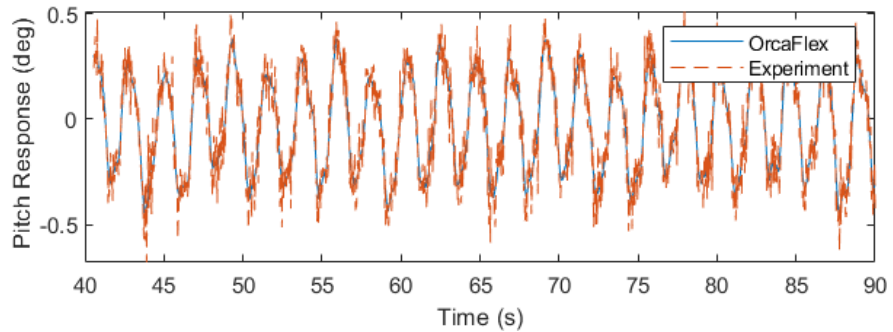

FIGURE 10 WAVE ELEVATION TIME HISTORY, SURGE AND PITCH RESPONSES FOR A REGULAR

WAVE.

Figure 10 (a) between 10 and $30 \mathrm{~s}$ shows a build-up period where the wave conditions are steadily ramped up from zero in order to avoid transients at the beginning of the simulation. Therefore, Figs. 10 (b) and (c) shown from $40 \mathrm{~s}$ onwards avoiding the above-mentioned build-up period.

\subsection{Irregular wave tests}

Figures 11 presents the wave height time series and the results of the numerical simulation for an irregular wave test with a significant wave height of $40 \mathrm{~mm}$ and peak wave period of $0.89 \mathrm{~s}$. The numerical simulation has not been forced to produce the same wave profile. However, both amplitude and frequency have been appropriately matched.

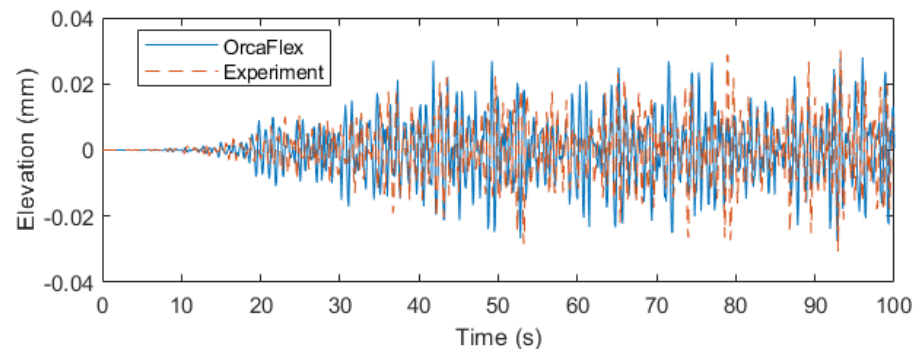

FIGURE 11 EXAMPLE OF WAVE HEIGHT TIME SERIES FOR IRREGULAR WAVE EXPERIMENT.

Figure 12 presents the surge and pitch response time histories for the same scenario.

(a)

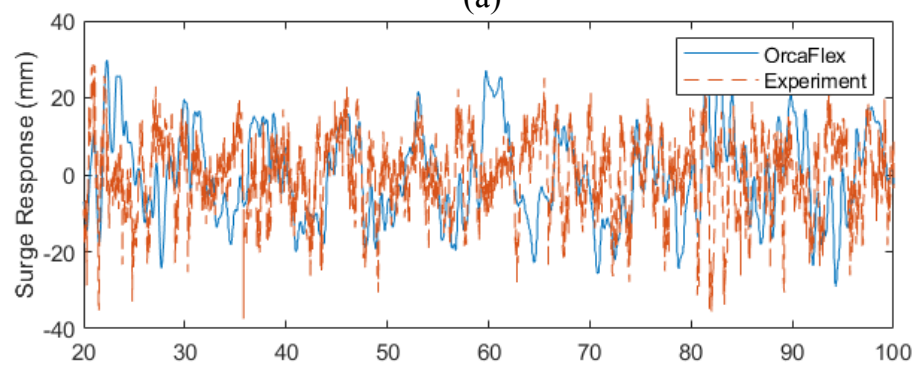

(b)

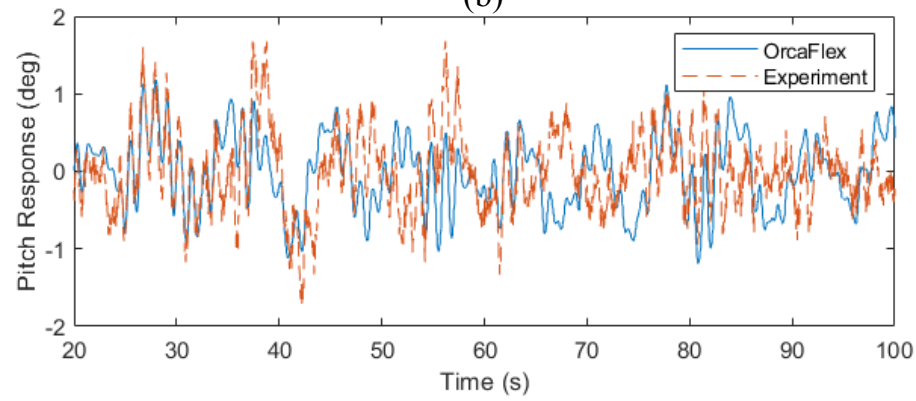

FIGURE 12 RESPONSE TIME HISTORIES FOR SURGE, AND PITCH MODES OF MOTION FOR THE IRREGULAR WAVE TIME SERIES SHOWN IN FIGURE

11.

Since the wave profile was not forced to be equal, the response time-series do not match although the frequency of the numerical response fits well with the experimental one.

Figure 13 presents the simulated and experimental wave height, surge, and pitch spectral densities for the above mentioned irregular wave. The power spectral density graphs show good agreement between the experimental results and numerical simulations. 

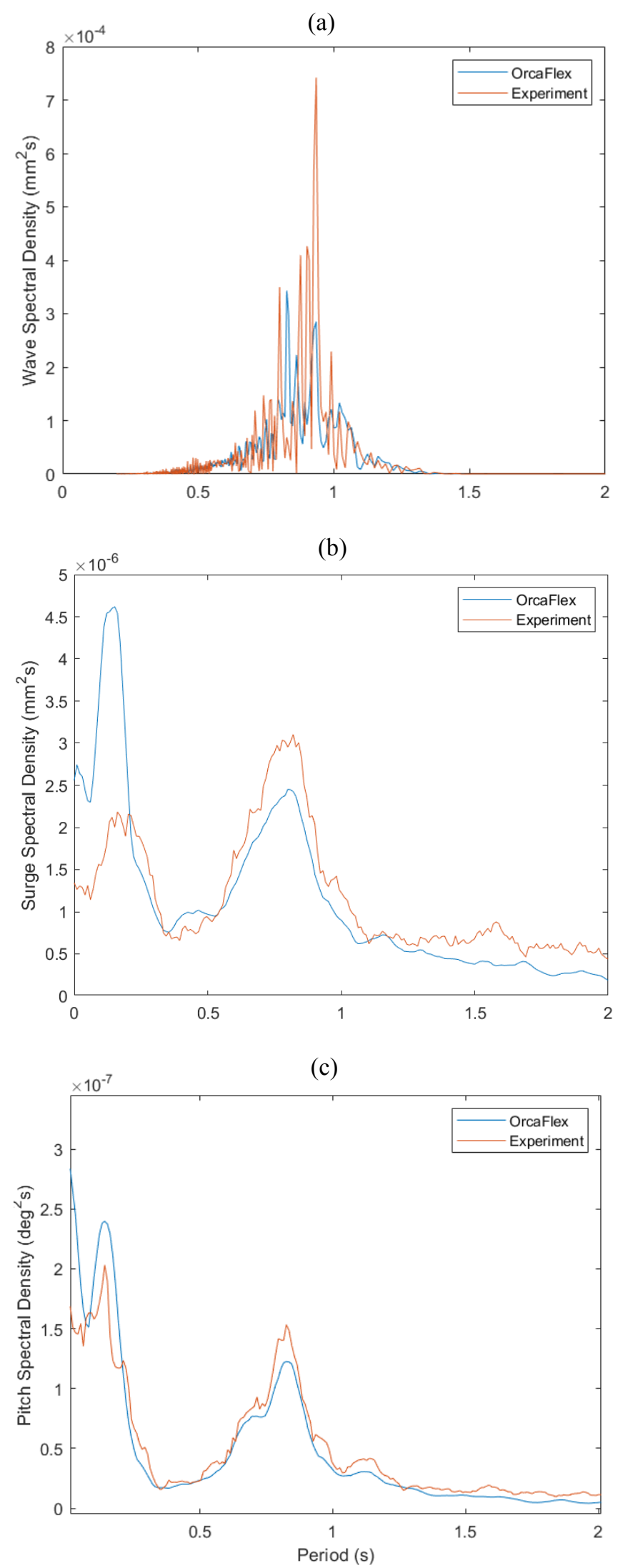

FIGURE 13 SIMULATED AND EXPERIMENTAL WAVE HEIGHT, SURGE, AND PITCH SPECTRUM.
Figure 3 (a) presents good agreement in terms of frequency content although the simulated spectral amplitudes are off by $50 \%$. Since the frequency content in the excitation is well matched, the agreement shown in Figs. 3 (b) and (c) means that the transfer functions used by the numerical model are reliable.

\section{CONCLUSIONS}

Hydrodynamic testing of a 1:45 Froude scaled model of the DTI-F concept has been carried out. Free decay, stiffness decay, regular wave, and irregular testing were performed. The hydrostatic behaviour and resonance properties of the floater were experimentally determined and used to calibrate a numerical model developed in ANSYS AQWA. ANSYS AQWA submerged volume calculation fits the measured model weight. Validated ANSYS AQWA outputs were used as an input in OrcaFlex. The hydrodynamic response of the moored system was tested and used to calibrate the OrcaFlex numerical model.

Regarding the wave quality, the requested wave periods were adequately reproduced in the basin, but the amplitudes were $23 \%$ off for the lower amplitudes arising until $27 \%$ of for the higher amplitudes.

Free decay measurements show good agreement with the ANSYS AQWA simulation results confirming the validity of the diffraction-radiation model developed.

The stiffness decay experiments show good agreement with the OrcaFlex simulations and the mooring line tensions match the testing measurements.

Stiffness decay tests served as justification for the mooring configuration choice. Since no improvement regarding natural periods of oscillation was achieved by increasing the number of mooring lines nor by including the delta connection, the three mooring lines configuration was selected.

The full-scale natural period results show that all six degrees of freedom are longer than the linear wave excitation, as the ocean waves contain first harmonic wave energy in the period range of 5 - 25 seconds.

For a spar buoy-based FOWT the natural periods in surge, sway and yaw should be larger than 100 seconds, 20-35 seconds for heave, and 50-90 seconds for roll and pitch [18]. Therefore, the results meet the constraints specified in the relevant standards.

Comparing the results to the Equinior's (former Statoil) Hywind project results $[19,20]$, the DTI-F concept has a $25 \%$ longer surge period, a similar heave period, a $75 \%$ longer pitch and roll periods, and a $95 \%$ longer yaw period.

The good agreement shown between regular and irregular wave testing and the OrcaFlex simulation gives confidence in the overall numerical model.

Further work comprises:

1. The validation of the height of the CoG by performing an inclination test on the model.

2. The validation of the inertia moments by performing a swing test on the model. 
3. Coupling the aeroelastic model of the Levenmouth offshore wind turbine [16] with the OrcaFlex model to produce fully-coupled simulations.

4. Perform software-in-the-loop testing to validate the results of the coupled simulation.

\section{ACKNOWLEDGEMENTS}

This work has received support from:

1. MaRINET2 - European Union's Horizon 2020 research and innovation programme under grant agreement number 731084 .

2. Floating Wind Turbines Limited (FWT Ltd).

3. The Energy Technologies Institute (ETI); Research Councils UK (RCUK); Energy Programme for the Industrial Doctorate Centre for Offshore Renewable Energy (IDCORE) [grant number EP/J500847/1].

\section{REFERENCES}

[1] BP plc (2018). Statistical Review of World Energy 2018 [online] Available at:

https://www.bp.com/content/dam/bp/en/corporate/pdf/energyeconomics/statistical-review/bp-stats-review-2018-fullreport.pdf [Accessed 4 Sep. 2018].

[2] ORE Catapult (2018). Floating wind: technology assessment. [online] Available at: https://ore.catapult.org.uk/app/uploads/2018/01/Floating-windtechnology-assessment-June-2015.pdf [Accessed 4 Sep. 2018].

[3] Cordle, A. and Jonkman, J. (2011). State of the Art in Floating Wind Turbine Design Tools. Proceedings of the 21st International Offshore and Polar Engineering Conference. [online] Available at: https://www.nrel.gov/docs/fy12osti/50543.pdf [Accessed 20 Nov. 2018].

[4] Benitz, M., Schmidt, D., Lackner, M., Stewart, G., Jonkman, J. and Robertson, A. (2014). Comparison of Hydrodynamic Load Predictions Between Reduced Order Engineering Models and Computational Fluid Dynamics for the OC4-DeepCwind Semi-Submersible. Volume 9B: Ocean Renewable Energy.

[5] Tran, T. and Kim, D. (2017). A CFD study of coupled aerodynamic-hydrodynamic loads on a semisubmersible floating offshore wind turbine. Wind Energy, 21(1), pp.70-85.

[6] Cermelli, C., Leroux, C., Díaz Domínguez, S. and Peiffer, A. (2018). Experimental Measurements of WindFloat 1 Prototype Responses and Comparison With Numerical Model. Volume 10: Ocean Renewable Energy.

[7] Serret, J., Tezdogan, T., Stratford, T., Thies, P.R. and Venugopal, V. (2018). Model test of the DTI-Floating wind concept. Proceedings of the 3rd International Conference on Offshore Renewable Energy. [online] Available at: https://strathprints.strath.ac.uk/65393/1/Serret_etal_CORE2018 Model test of the DTI Floating wind concept.pdf

[Accessed 15 Oct. 2018].

[8] Lopez-Pavon, C. and Souto-Iglesias, A. (2015). Hydrodynamic coefficients and pressure loads on heave plates for semi-submersible floating offshore wind turbines: A comparative analysis using large scale models. Renewable Energy, 81, pp.864-881.

[9] Nielsen, F., Hanson, T. and Skaare, B. (2006). Integrated Dynamic Analysis of Floating Offshore Wind Turbines. Volume 1: Offshore Technology; Offshore Wind Energy; Ocean Research Technology; LNG Specialty Symposium.

[10] Kvittem, M., Berthelsen, P., Eliassen, L. and Thys, M. (2018). Calibration of Hydrodynamic Coefficients for a SemiSubmersible 10 MW Wind Turbine. Volume 10: Ocean Renewable Energy.

[11] Oguz, E., Clelland, D., Day, A., Incecik, A., López, J., Sánchez, G. and Almeria, G. (2018). Experimental and numerical analysis of a TLP floating offshore wind turbine. Ocean Engineering, 147, pp.591-605.

[12] Jonkman, J. and Matha, D. (2011). Dynamics of offshore floating wind turbines-analysis of three concepts. Wind Energy, 14(4), pp.557-569.

[13] Aghaalikhani, A., Arsuffi, G., Borello, D. and Rispoli, F. (2016). Offshore floating wind turbines for Mediterranean sites: Preliminary analysis of different concepts. Wind Engineering, 40(5), pp.475-480.

[14] Azcona, J., Palacio, D., Munduate, X., González, L. and Nygaard, T. (2016). Impact of mooring lines dynamics on the fatigue and ultimate loads of three offshore floating wind turbines computed with IEC 61400-3 guideline. Wind Energy, 20(5), pp.797-813.

[15] Fassardi, C. (2002). Tank testing and data analysis techniques for the assessment of sailboat hydrodynamic characteristics. [online] Available at: http://vm2330.sgvps.net/ syrftest/images/library/20150702141 832.pdf [Accessed 20 Nov. 2018].

[16] Serret, J. (2018). Code comparison of a NREL-FAST model of the Levenmouth wind turbine with the GH Bladed commissioning results. Proceedings of the ASME 2018 37th International Conference on Ocean, Offshore and Arctic Engineering. [online] Available at: http://proceedings.asmedigitalcollection.asme.org/proceeding.a spx? articleid $=2704882$ [Accessed 20 Nov. 2018].

[17] Harnois, V., Weller, S., Johanning, L., Thies, P., Le Boulluec, M., Le Roux, D., Soulé, V. and Ohana, J. (2015). Numerical model validation for mooring systems: Method and application for wave energy converters. Renewable Energy, 75, pp.869-887.

[18] DNV Recommended Practice DNV-RP-F205, Global Performance Analysis of Deepwater Floating Structures, October 2010

[19] Driscoll, F., Jonkman, J., Robertson, A., Sirnivas, S., Skaare, B. and Nielsen, F. (2016). Validation of a FAST Model of the Statoil-hywind Demo Floating Wind Turbine. Energy Procedia, 94, pp.3-19.

[20] Driscoll, F., Jonkman, J., Robertson, A., Sirnivas, S., Skaare, B. and Nielsen, F. (2016). Validation of a FAST Model of the Statoil-hywind Demo Floating Wind Turbine. Energy Procedia, 94, pp.3-19. 